\title{
Article \\ Effects of Learning Attitudes and COVID-19 Risk Perception on Poor Academic Performance among Middle School Students
}

\author{
Jaewon Lee ${ }^{1}$, Hyejung Lim ${ }^{2, *}$, Jennifer Allen ${ }^{3}$ and Gyuhyun Choi ${ }^{4}$ \\ 1 Department of SocialWelfare, Inha University, Incheon 22212, Korea; j343@inha.ac.kr \\ 2 School of Education, Korea University, Seoul 02841, Korea \\ 3 School of Social Work, Michigan State University, East Lansing, MI 48823, USA; allenj66@msu.edu \\ 4 Integrative Arts Therapy, Dongduk Women's University, Seoul 02748, Korea; toyou4048@uos.ac.kr \\ * Correspondence: nanapro@korea.ac.kr
}

\section{check for}

updates

Citation: Lee, J.; Lim, H.; Allen, J.; Choi, G. Effects of Learning Attitudes and COVID-19 Risk Perception on Poor Academic Performance among Middle School Students. Sustainability 2021, 13, 5541. https://doi.org/ $10.3390 /$ su13105541

Academic Editors:

Antonio-Manuel Rodríguez-García,

María-Natalia Campos-Soto and Juan Carlos de la Cruz-Campos

Received: 6 April 2021

Accepted: 13 May 2021

Published: 16 May 2021

Publisher's Note: MDPI stays neutral with regard to jurisdictional claims in published maps and institutional affiliations.

Copyright: (c) 2021 by the authors. Licensee MDPI, Basel, Switzerland. This article is an open access article distributed under the terms and conditions of the Creative Commons Attribution (CC BY) license (https:// creativecommons.org/licenses/by/ $4.0 /)$.

\begin{abstract}
The purpose of this study is to examine the effects of middle school students' learning attitudes and risk perception toward COVID-19 on their poor academic performance since the COVID-19 pandemic began. This study limited the sample to middle school students who responded that their academic performance was an A or B grade during the last academic year in 2019. For this study, 268 respondents were selected and logistic regression was employed. Self-motivated studying time and positive attitudes toward online learning predicted consistent academic performance since the COVID-19 pandemic began. Middle school students' preference toward an in-person classroom format was related to poor academic performance since the COVID-19 pandemic began. A risk perception toward COVID-19 was related to poor academic performance since the COVID-19 pandemic began. It is imperative to provide educational programs which help students develop selfmotivated studying habits to maintain their academic performance during COVID-19. Policymakers in schools should consider providing in-person options for students who are more academically successful in such an environment.
\end{abstract}

Keywords: COVID-19; learning attitudes; academic performance; middle school students

\section{Introduction}

Since the emergence of the COVID-19 pandemic, students at schools around the world, including in South Korea, have faced challenges related to shifts to online learning, either full-time or in a hybrid model that blends online and part-time, in-person instruction [1]. Researchers have found that such shifts to online schooling are effective at decreasing the spread of COVID-19 infection [2]. Researchers have also found that these social distancing measures greatly affect adolescents' mental, physical and emotional health [3-6]. Shifts toward online learning may also impact adolescents' attitudes toward learning, motivation to learn and academic performance [7-9]. Therefore, it is important to examine the extent to which adolescents engage in protective behaviors against COVID-19 as well as their attitudes toward online learning, motivation to learn, and academic performance since the COVID-19 pandemic began.

\section{Literature Review}

\subsection{Academic Performance and the COVID-19 Pandemic}

Researchers have found that academic performance, demonstrated through standardized test scores, has decreased among some students since the emergence of the COVID-19 pandemic [10]. In a sample of $15 \%$ of all schools in the Netherlands, researchers examined differences in scores on reading comprehension, math and spelling among students aged 7-11 years from 2017 to 2020 [10]. From 2017 to 2019, the scores on the twice-yearly tests showed no significant difference; however, in 2020, upon the beginning of the COVID-19 pandemic, students' overall scores dropped by three percentile points in math, spelling 
and reading [10]. Most of the literature on academic performance during COVID-19 has examined postsecondary students, with little else known on the effect of COVID-19 on the academic performance of middle schoolers specifically.

\subsection{Learning Attitudes and Academic Performance during COVID-19}

Positive attitudes toward learning during COVID-19 have been found to be associated with higher academic performance [7-9,11,12]. Positive attitudes toward learning during COVID-19 may include self-motivated learning as well as positive attitudes toward, or a preference toward, online learning versus an in-person format. In one study, parents of students in grades one through nine in Italy and Portugal reported on their children's academic motivation, and latent score change models showed that students' motivation decreased in both countries since the COVID-19 pandemic emerged [9]. Additionally, among postsecondary students in Malaysia, motivation to learn dropped significantly during a period when the government restricted travel and other non-essential activities to reduce the spread of the virus [8]. Moreover, it was found that among these students, motivation to learn was strongly, positively associated with academic performance [8].

While no study was found that directly examined the relationship between positive attitudes toward online learning and academic performance among adolescents during COVID-19, one study did reveal that if college students strongly preferred face-to-face learning, they were more likely to struggle to adapt to online learning [7]. These students that preferred face-to-face learning also reported lower cognitive engagement in online learning [7]. Both of these factors - a preference toward face-to-face learning during a period of mandatory online learning and lower cognitive engagement in their online courses-may influence their academic performance.

\subsection{COVID-19 Risk Perception and Academic Performance}

Researchers in Canada and Italy examined adolescents' and young adults' perceived risk of COVID-19 infection and found that, overall, young people did not consider themselves to be at high risk for infection, although young people in Canada did consider their family and friends to be at a higher risk than themselves $[13,14]$. Additionally, higher risk perception of COVID-19 infection was associated with increased odds of participating in protective measures against COVID-19, such as washing one's hands and social distancing [14]. However, despite fewer young people seemingly concerned about their own risk of COVID-19 infection, in a sample of Turkish college students, nearly 70\% reported feeling anxious about the spread of COVID-19, which was associated with a decreased motivation to study, which may in turn lead to decreased academic performance [15].

\subsection{Resilience among Adolescents Amid the COVID-19 Pandemic}

Despite the challenges faced by adolescents around the world since the COVID-19 pandemic began, researchers have observed resilience, or the ability to overcome or bounce back from challenges, among adolescents [16]. In fact, some researchers say that experiencing some adversity assists with developing the resiliency processes needed to bounce back [16]. Additionally, researchers have found that being more resilient is associated with fewer negative psychological outcomes, such as depression, anxiety and stress, since the pandemic emerged [17]. Increased resilience has also been found to be associated with higher academic performance; these studies were conducted prior to COVID-19, but they considered stressful environments such as severe poverty, homelessness and placement in residential or foster care $[18,19]$. Therefore, fostering resilience in adolescents is of high importance to temper the negative psychological and academic impacts they may experience due to the COVID-19 pandemic [20].

\subsection{Theoretical Framework and Education in South Korea}

The unprecedented COVID-19 pandemic has greatly influenced life for many people. In South Korea, where the school year typically runs from March to February, the emergence 
of the COVID-19 pandemic caused the school year to be delayed by five weeks, before beginning in April 2020 in a virtual format [1]. Students did not begin to return to school in person until June 2020 and, until then, families faced challenges such as relatively few parents $(60 \%)$ being able to work from home even some of the time [1]. For middle school students in South Korea, one of the main achievements in life is academic performance, and the negative effects of the coronavirus may also affect middle school students' grades. The Ecological Systems Theory explains human behavior by considering the influence of multiple levels such as individual, social-environmental and cultural aspects [21]. This theory exphasizes the dynamic mutual interactions between individuals and the environment based on open systems [22]. That is, environmental changes caused by COVID-19 may negatively influence individuals' academic performance. In particular, students in South Korea already encounter many stresses concerning high academic expectations, such as through parents or "tiger moms" who put an immense amount of pressure on children for high educational attainment and performance [23]. Given that fierce academic competition has existed in South Korea for a long time [24], the environmental changes due to COVID19 , such as online lectures instead of face-to-face class, may increase students' stresses regarding their academic performance. Thus, this study focuses on how middle school students adjust to their new learning environment and how they have been influenced by COVID-19, based on the Ecological Systems Theory.

\section{The Current Study}

The COVID-19 pandemic has influenced individuals' lives on various dimensions, such as education, economics and equality, regardless of generation [25]. In particular, students have faced a dramatic change in their learning format. The effectiveness of a hybrid learning model and middle school students' academic performance may be influenced by their attitudes towards learning. In addition, during the period of coronavirus outbreak, risk perception toward COVID-19 may also affect their academic performance. Even though the middle school years are an important developmental bridge between elementary school and high school, little is known about how COVID-19 and attitudes on learning among middle school students influence their academic performance. Particularly, this study focuses on middle school students whose previous grades were A or B before COVID-19 (during the 2019 academic year) and how they displayed poor academic performance since the COVID-19 pandemic began. Thus, the purpose of this study is to (1) examine relationships between middle school students' learning attitudes and their poor academic performance since the COVID-19 pandemic began and (2) explore the association between risk perception toward COVID-19 and middle school students' poor academic performance since the COVID-19 pandemic began.

\section{Methods}

\subsection{Participants and Study Settings}

The target population of this study is middle school students in South Korea, and the research team used an official online outlet to recruit students. The online platform is an official communication tool between all public middle schools and students. The research team posted a link about the survey on the online platform. Respondents in this study are middle school students at a public middle school in Gyeonggi province, South Korea. Data were collected October 2020. Google Forms was used to create the structured questionnaire. Survey items were checked by experts, including middle school teachers, to enhance the quality of the questionnaires and to protect participants from any risks of survey participation. The refined survey was distributed to middle school students and respondents received a $\$ 2$ gift card as a reward. A total of 354 middle school students engaged in this survey. However, as the primary focus of this study is to identify what factors led to poor academic performance in the spring semester of 2020 among students who received high grades (such as an A or B) last academic year, this study limited the sample to middle school students who responded that their academic performance was an 
A or B grade during the last academic year in 2019. Two hundred sixty-eight respondents were selected for the final sample while the remaining 86 participants were excluded because they received a lower grade than $B$. As this study does not include any private information such as name, address, contacts and the like, the Institutional Review Board (\#200810-1A) approved this research.

\subsection{Measures}

Poor academic performance since COVID-19. Respondents were queried about their levels of academic success during the spring semester of 2020, which is when COVID-19 emerged. They were asked to answer whether they received an A+, A, B+, B, C+, C, D+ or lower grade. The grades indicate a cumulative GPA for all classes the students took. Given that all participants in this study received $\mathrm{A}+, \mathrm{A}, \mathrm{B}+$ or $\mathrm{B}$ before the coronavirus outbreak, those who received grades lower than B since the COVID-19 pandemic began were classified into the poor academic performance group.

Risk perception toward COVID-19. Middle school students were asked to what extent they are aware of the risks of COVID-19. Four items measuring the level of perceived risks of COVID-19 were used to measure the risk perception toward COVID-19, and this scale was rated on a five-point Likert-type scale. Five response options were provided to respondents ranging from 1 (strongly disagree) to 5 (strongly agree). The four items were as follows: COVID is different from the flu and may have unidentified symptoms, so I am scared that I will get COVID-19; I am feeling a sense of risk about COVID-19 because we do not know when we can overcome the coronavirus and when COVID-19 will be eradicated; COVID-19 would damage my health; I am scared about negative effects of COVID-19 as it has limited my daily life activities (e.g., decreased frequency of dining out or meeting friends in person). The mean of all items was used, and lower scores indicated a lower risk perception toward COVID-19. The Cronbach's $\alpha$ of the five-point Likert-type scale was $0.73(M=4.24 ; S D=0.71)$.

Learning attitudes. Learning attitudes in this study are defined as a positive attitude toward learning, indicating an individual's capability and willingness to learn under the new educational format required due to the COVID-19 pandemic. In this study, selfmotivated studying, acceptance of online -learning and preferences about classroom format or online learning comprise the learning attitudes since the COVID-19 pandemic began.

Self-motivated studying. Participants were asked how many hours they study a week, without any pressure from parents or caregivers.

Attitudes toward online learning. Respondents responded to what extent they have a positive attitude about accepting online learning as a new educational format. This measure consisted of five items with a five-point Likert-type scale with the following response options: strongly disagree, disagree, neutral, agree or strongly agree. Scale items included "I stay focused when listening to an online lecture"; "I am willing to answer a question from teachers and to participate in a presentation during an online lecture"; "I am actively submitting assignments during the period of an online lecture based upon guidelines the teachers provided"; "I try to preview the materials I will learn tomorrow in order to reduce difficulties that occur during an online lecture (e.g., decreased communications and Q\&A time with teachers compared to face-to-face class)"; "I try to review what I learned yesterday in order to minimize challenges that occur during online lectures (e.g., fewer chances to ask questions to teachers compared to face-to-face class)." The average score of each item was used with higher scores indicating a more positive attitude toward online learning. This scale had a Cronbach's alpha of $0.81(M=3.57$; $S D=0.79)$.

Preference about class format. Middle school students were asked to respond to the following: "I like to take classroom training in person compared to online learning through Zoom". They responded to this question with one of five response options: strongly disagree, disagree, neutral, agree or strongly agree. Higher scores show a greater preference for an in-person classroom format $(M=3.58$; $S D=1.31)$. 
Control variables. Age, gender, subjective poverty, resilience and peer relationships were included as control variables. Subjective poverty was measured by using the Leyden Poverty Line [26]. Participants were asked, "In your circumstances, do you consider your household's economic status to be good or bad?" They selected one of six response options: very bad, bad, insufficient, sufficient, good and very good. Resilience was measured via the Brief Resilience Scale (BRS) [27]. This scale consists of six items with a five-point Likert-type scale. Three items were reverse-coded before analysis. Higher scores indicate greater resilience. Last, peer relationships were measured by the Hemingway Measure of Adolescent Connectedness [28]. Six items with a five-point Likert-type scale were used and one of the items were reverse-coded. Higher scores indicate more positive peer relationships.

\subsection{Analysis Strategy}

Descriptive statistics were considered and logistic regression was conducted to investigate the associations between attitudes on learning and poor academic performance and between risk perception toward COVID-19 and poor academic performance. Logistic regression was employed and the Statistical Package for the Social Sciences (SPSS) 26.0 was used for analyses.

\section{Results}

Descriptive statistics are shown in Table 1. Girls made up 52.2\% of the total sample while boys made up $47.8 \%$. The average age of the middle school students who participated in this study was 14.3 years old. The average scores for subjective poverty, resilience and peer relationship were 4.11,3.30 and 3.93, respectively. Among middle school students who responded that their academic performances were an A or B grade before COVID-19, 11.6\% reported that they received lower than a B grade since the COVID-19 pandemic began (i.g., 31 students). For attitudes on learning, the average hours of self-motivated studying a week were 10.3. The average scores of attitudes on online learning and preference about classroom format were 3.57 and 3.58, respectively. The average score of risk perception toward COVID-19 was 4.24.

Table 1. Descriptive Statistics for Variables Included in the Study.

\begin{tabular}{cc}
\hline Variables & Total \\
\hline & $(\mathrm{n}=268)$ \\
\hline Poor academic performance since the COVID-19 pandemic began & $11.6 \%$ \\
Risk perception toward COVID-19 & $4.24(0.71)$ \\
Learning attitudes & \\
Self-motivated studying & $10.30(13.08)$ \\
Attitudes toward online learning & $3.57(0.79)$ \\
Preference about class format & $3.58(1.31)$ \\
Age & $14.34(1.06)$ \\
Gender (girls) & $52.2 \%$ \\
Subjective poverty & $4.11(0.89)$ \\
Resilience & $3.30(0.88)$ \\
Peer relationships & $3.93(0.67)$ \\
\hline
\end{tabular}

Results of the logistic regression are shown in Table 2. Demographic variables did not significantly affect academic performance. However, lower resilience and poorer peer relationships predicted a decrease in academic performance since the COVID-19 pandemic began $(\mathrm{OR}=0.52, p<0.05 ; \mathrm{OR}=0.24, p<0.01)$. In other words, a one-unit decrease in resilience predicted a 0.52 increase in the likelihood that academic performance would be poor since the COVID-19 pandemic began, while a one-unit decrease in peer relationships resulted in a 0.24 increase in the likelihood that academic performance would be poor since the COVID-19 pandemic began. In terms of learning attitudes during the COVID19 pandemic, more self-motivated studying time and positive attitudes toward online 
learning predicted consistent academic performance since the COVID-19 pandemic began $(\mathrm{OR}=0.88, p<0.05 ; \mathrm{OR}=0.46, p<0.05)$. Middle school students' preference toward an in-person classroom format was related to a decrease in academic performance since the COVID-19 pandemic began (OR $=1.81, p<0.01)$. Further, a higher risk perception toward COVID-19 was significantly related to a decrease in academic performance since the COVID-19 pandemic began (OR $=2.25, p<0.05)$.

Table 2. Logistic Regression Coefficients (Odds ratio) Predicting Poor Academic Performance.

\begin{tabular}{ccccc}
\hline Variables & Poor Academic Performance & \multicolumn{2}{c}{$\mathbf{9 5 \%}$ CI } \\
\hline (Constant) & $\mathbf{1 0 . 8 0}(\mathbf{5 . 9 9 )}$ & & Lower & Upper \\
\hline Age & $-0.67(0.51)$ & & 0.24 & 1.12 \\
Gender (girls) & $-0.47(0.62)$ & & 0.23 & 1.70 \\
Subjective poverty & $0.46(1.58)$ & & 0.90 & 2.77 \\
Resilience & $-0.65(0.52)$ & $*$ & 0.28 & 0.98 \\
Peer relationships & $-1.43(0.24)$ & $* *$ & 0.10 & 0.57 \\
Learning attitudes & $0.81(2.25)$ & $*$ & 1.05 & 4.79 \\
Risk perception toward COVID-19 & & & & \\
Self-motivated studying & $-0.13(0.88)$ & $*$ & 0.79 & 0.98 \\
Attitudes toward online learning & $-0.77(0.46)$ & $*$ & 0.23 & 0.94 \\
Preference about class format & $0.59(1.81)$ & $* *$ & 1.18 & 2.79 \\
\hline
\end{tabular}

Note. CI $=$ Confidence Interval, ${ }^{*} p<0.05$. ${ }^{* *} p<0.01$.

\section{Conclusions and Discussion}

The primary purpose of the current study was to explore how learning attitudes and risk perception toward COVID-19 influence poor academic performance, since the COVID-19 pandemic began, among middle school students. In particular, the middle school students in this study were limited to those who received A or B grades before COVID-19. That is, this study reveals how attitudes toward learning have changed since the COVID-19 pandemic began and how risk perception toward COVID-19 led to lower grades among students who received high grades before COVID-19. Because middle school students are not as mature as adults and the period during middle school is critical in the developmental stage, they may be more likely to be greatly influenced by the unprecedented COVID-19 pandemic $[6,29,30]$. Thus, it is important to understand middle schoolers' changes in academic performance since the COVID-19 pandemic began. However, little evidence exists identifying what factors influence students' decreased grades since the COVID-19 pandemic began. This study revealed that two factors-learning attitudes and risk perception toward COVID-19-were significantly associated with poor academic performance.

As the coronavirus pandemic has rapidly expanded and public schools have used online learning to avoid unnecessary contact in person, students' learning attitudes may change and therefore their attitudes are considerably important to academic performance. This study indicated that attitudes toward online learning, preferences about classroom format and self-motivated studying time influenced middle school students' poor academic performance. In particular, the learning attitudes considered in this study should be given more attention because such attitudes negatively affected the grades of middle school students who received A or B grades before COVID-19. There is a large body of research identifying how attitudes toward learning influences academic performance [31-33]. However, little is known about how learning attitudes lead to poor academic performance over the coronavirus pandemic, particularly among middle school students.

Middle school students in this study were regarded as high-achieving students receiving A or B grades before COVID-19; however, for some, their performance worsened since the COVID-19 pandemic began, receiving lower than a B. This study confirmed that self-motivated studying is important to maintain good grades based on self-directed learning without support or monitoring from parents [34,35] and this is also significant during the COVID-19 pandemic. As self-motivated studying results in more active par- 
ticipation in learning and confidence in what was learned [36], it is imperative to provide educational programs which help middle school students develop self-motivated studying habits to maintain their academic performance during the COVID-19 pandemic. Further, as we continue to experience the unprecedented coronavirus pandemic, it is necessary to take into account students' negative attitudes about online learning and preference regarding classroom format. During the COVID-19 pandemic, middle school students who were more likely to accept the online educational system were able to keep their good grades from before COVID-19 by receiving an A or B. In other words, it is important for middle school students to adjust to the new educational environment and to mutually communicate with teachers and friends through the online learning system. This might be influenced by a teacher's ability to encourage students to actively participate in class. Thus, training or educational modules for teachers on online teaching should be prepared and provided to teachers in public schools. On the other hand, middle school students who are reluctant to participate in online learning and who prefer to take their classes in person are more likely to receive low grades during the COVID-19 pandemic, even when they received good grades before COVID-19. Therefore, middle schools might consider providing in-person options for such students who are more academically successful in such an environment.

Moreover, this study revealed that students who had greater risk perception concerning COVID-19 were more likely to show poor academic performance since the COVID-19 pandemic began, even though they received A or B grades before COVID-19. The risk perception may bring about more anxiety, stress and a sense of discomfort, which may be an obstacle to learning. That is, middle school students who are more worried about coronavirus infection might have or develop mental health symptoms, and these symptoms may lead to poorer academic performance [37,38]. There are other factors that may result in poor academic achievement, such as peer relationships, teachers' instructional style and socioeconomic status $[39,40]$. However, during the COVID-19 pandemic, it is important to understand the influence of coronavirus as a factor to identify how middle school students' grades negatively changed. This aligns with an argument of the Ecological Systems Theory, indicating that social environmental factors mutually interact with individuals' lives [21,22]. In other words, this theory implies that we need to pay more attention to the impact of multiple levels of the enviroment; therefore, this study takes into account the effects of COVID-19 to understand changes of academic performance since the COVID-19 pandemic began. The unexpected emergence of COVID-19 as a new environmental factor influences middle school students' academic performance as they are forced to change their learning and studying enviroments from face-to-face to online. Further, limited daily life activities, such as decreased communication with peers, can also affect their academic performance. To reduce the negative impact of high risk perception among middle school students, mental health services should be provided to them to relieve their anxiety about COVID-19, helping them to focus on their learning. Further, middle school students are not fully mature and have a decreased ability to manage their stress or anxiety associated with coronavirus. Therefore, support from teachers and parents might be important to reduce middle school students' anxiety or stress related to the risk of COVID-19, helping them to maintain good grades.

Additionally, the current study reported that middle school students who had greater resilience and peer relationships were less likely to experience poor academic performance since the COVID-19 pandemic began. Individuals who have greater resilience are likely to overcome an adversity or threats [41] and adjust themselves to the new environment. As COVID-19 can be regarded as a major adversity for humankind, middle school students with greater resilience can more easily adapt their daily lives, including their learning. In addition, middle school students who have built good relationships with their peers tend to have greater academic achievement [42]. Those who have peers with positive attitudes toward learning may be more likely to develop more positive learning attitudes themselves, and this plays a role as a buffer against poor academic performance since the COVID-19 
pandemic began. However, students with peers who have negative attitudes toward education are likely to be affected by their peers' attitudes as well. Therefore, increasing resilience and developing positive peer relationships among middle school students is important to maintain good academic performance during the coronavirus pandemic.

This study contributes to understanding changes in academic performance before and after COVID-19. However, readers should recognize limitations of this study. First, as participants in this study are limited to middle school students in South Korea, cultural differences or differences in educational systems should be considered to understand academic performance in other cultures. Second, there are a variety of factors which may influence academic achievement; however, this study did not include all possible covariates. Third, middle school students from low-income households are not specifically considered in this study, and they may show different characteristics and different results in academic performance. Thus, we recommend that future studies should target low-income middle school students. Fourth, as preference about class format includes one item, we could not report the validity or reliability of this scale. Thus, we suggest that a standardized measurement should be used in future studies. Fifth, those who were classified into the poor academic performance group consisted of $11.6 \%$ of the total population. The number of the students in the group is small, so we recommend that future studies increase the total sample size and have an increased number of students who reported a decrease in academic performance. Sixth, a self-reported item on academic performance was used. Thus, social desirability bias might have influenced students' responses. Last, the Ecological Systems Theory is useful to understand this study, but it partially explains the logic of this study. Thus, an advanced theoretical framework or mixed combination of multiple theories is needed to profoundly illuminate poor academic performance among middle school students since the COVID-19 pandemic began.

Author Contributions: The authors contributed equally to this study. All authors have read and agreed to the published version of the manuscript.

Funding: This research received no external funding.

Institutional Review Board Statement: The study was conducted according to the guidelines of the Declaration of Helsinki, and approved by the Institutional Review Board of Inha University (protocol code \#200810-1A).

Informed Consent Statement: Informed consent was obtained from all subjects involved in the study.

Data Availability Statement: The data used in this study is available on request from the corresponding author.

Conflicts of Interest: The authors declare no conflict of interest.

\section{References}

1. Byun, S.; Slavin, R.E. Educational Responses to the COVID-19 Outbreak in South Korea. Best Evid. Chin. Edu. 2020, 5, 665-680. [CrossRef]

2. McGrail, D.J.; Dai, J.; McAndrews, K.M.; Kalluri, R. Enacting National Social Distancing Policies Corresponds with Dramatic Reduction in COVID19 Infection Rates. PLoS ONE 2020, 15. [CrossRef]

3. Bates, L.C.; Zieff, G.; Stanford, K.; Moore, J.B.; Kerr, Z.Y.; Hanson, E.D.; Gibbs, B.B.; Kline, C.E.; Stoner, L. COVID-19 Impact on Behaviors Across the 24-h Day in Children and Adolescents: Physical Activity, Sedentary Behavior, and Sleep. Children 2020, 7 , 138. [CrossRef]

4. Ellis, W.E.; Dumas, T.M.; Forbes, L.M. Physically Isolated but Socially Connected: Psychological Adjustment and Stress Among Adolescents During the Initial COVID-19 Crisis. Can. J. Behav. Sci. 2020, 52, 177-187. [CrossRef]

5. Guessoum, S.B.; Lachal, J.; Radjack, R.; Carretier, E.; Minassian, S.; Benoit, L.; Moro, M. Adolescent Psychiatric Disorders During the COVID-19 Pandemic and Lockdown. Psychiatry Res. 2020, 291. [CrossRef] [PubMed]

6. Xiang, M.; Zhang, Z.; Kuwahara, K. Impact of COVID-19 Pandemic on Children and Adolescents' Lifestyle Behavior Larger Than Expected. Prog. Cardiovasc. Dis. 2020, 63, 531-532. [CrossRef]

7. Aguilera-Hermida, A.P. College Students' Use and Acceptance of Emergency Online Learning Due to COVID-19. Int. J. Educ. Res. 2020, 1. [CrossRef] 
8. Tan, C. The Impact of COVID-19 on Student Motivation, Community of Inquiry and Learning Performance. Asian Educ. Dev. Stud. 2020. [CrossRef]

9. Zaccoletti, S.; Camacho, A.; Correia, N.; Aguilar, C.; Mason, L.; Alves, R.A.; Daniel, J.R. Parents' Perceptions of Student Academic Motivation During the COVID-19 Lockdown: A Cross-Country Comparison. Front. Psychol. 2020, 11. [CrossRef]

10. Engzell, P.; Frey, A.; Verhagen, M. Learning Inequality During the COVID-19 Pandemic. SocArXiv 2020. [CrossRef]

11. Fang, X. The Impact of Online Teaching on the English Learning Motivation of Chinese Students During COVID-19. In Proceedings of the International Symposium on Education, Culture and Social Sciences, Xi'an, China, 15-16 August 2020.

12. Hebebci, M.T.; Bertiz, Y.; Alan, S. Investigation of Views of Students and Teachers on Distance Education Practices During the Coronavirus (COVID-19) Pandemic. Int. J. Technol. Educ. Sci. 2020, 4, 267-282. [CrossRef]

13. Commodari, E.; La Rosa, V.L. Adolescents in Quarantine During COVID-19 Pandemic in Italy: Perceived Health Risk, Beliefs, Psychological Experiences and Expectations for the Future. Front. Psychol. 2020. [CrossRef] [PubMed]

14. Yang, X.Y.; Gong, R.N.; Sassine, S.; Morsa, M.; Tchogna, A.S.; Drouin, O.; Chadi, N.; Jantchou, P. Risk Perception of COVID-19 Infection and Adherence to Preventive Measures Among Adolescents and Young Adults. Children 2020, 7, 311. [CrossRef]

15. Elhadary, T.; Elhaty, I.A.; Mohamed, A.A.; Alawna, M. Evaluation of Academic Performance of Science and Social Science Students in Turkish Universities During COVID-19 Crisis. J. Crit. Rev. 2020, 7, 1740-1751.

16. Dvorsky, M.R.; Breaux, R.; Becker, S.P. Finding Ordinary Magic in Extraordinary Times: Child and Adolescent Resilience During the COVID-19 Pandemic. Eur. Child Adolesc. Psychiatry 2020. [CrossRef]

17. Zhang, C.; Ye, M.; Fu, Y.; Yang, M.; Luo, F.; Yuan, J.; Tao, Q. The Psychological Impact of COVID-19 Pandemic on Teenagers in China. J. Adolesc. Health 2020, 67, 747-755. [CrossRef]

18. Cutuli, J.J.; Desjardins, C.D.; Herbers, J.E.; Long, J.D.; Heistad, D.; Chan, C.-K.; Hinz, E. Academic Achievement Trajectories of Homeless and Highly Mobile Students: Resilience in the Context of Chronic and Acute Risk. Child Dev. 2013, 84, 841-857. [CrossRef]

19. Novotny, J.S.; Kremenkova, L. The Relationship Between Resilience and Academic Performance at Youth Placed at Risk. Cesk. Psychol. 2016, 60, 553-565.

20. Masten, A.; Motti-Stefanidi, F. Multisystem Resilience for Children and Youth in Disaster: Reflections in the Context of COVID-19. Advers. Resil. Sci. 2020, 1, 95-106. [CrossRef]

21. Bronfenbrenner, U.; Morris, P.A. The Ecology of Developmental Processes. In Handbook of Child Psychology: Vol. 1: Theoretical Models of Human Development; Damon, W., Lerner, R.M., Eds.; John Wiley and Sons: Hoboken, NJ, USA, 1998; pp. 993-1028.

22. Rothery, M. Critical Ecological Systems Theory. In Theoretical Perspectives for Direct Social Work Practice: A Generalist-Eclectic Approach; Coady, N., Lehmann, P., Eds.; Springer Publishing Company: New York, NY, USA, 2001; pp. 89-118.

23. Shin, M.; Wong, Y.J. Beyond the Tiger Mom: Asian American Parenting and Parent-Child Relationships. In Parenting: Challenges, Practices and Cultural Influences; Barberis, P., Petrakis, S., Eds.; Nova Science Publishers Inc.: Hauppauge, NY, USA, 2013; pp. 103-122.

24. Park, H.; Byun, S.Y.; Kim, K.K. Parental Involvement and Students' Cognitive Outcomes in Korea: Focusing on Private Tutoring. Sociol. Educ. 2011, 84, 3-22. [CrossRef]

25. Chakraborty, I.; Maity, P. COVID-19 Outbreak: Migration, Effects on Society, Global Environment and Prevention. Sci. Total. Environ. 2020, 728. [CrossRef] [PubMed]

26. Kapteyn, A.; Kooreman, P.; Willemse, R. Some Methodological Issues in the Implementation of Subjective Poverty Definitions. J. Hum. Res. 1988, 222-242. [CrossRef]

27. Smith, B.W.; Dalen, J.; Wiggins, K.; Tooley, E.; Christopher, P.; Bernard, J. The Brief Resilience Scale: Assessing the Ability to Bounce Back. Int. J. Behav. Med. 2008, 15, 194-200. [CrossRef]

28. Hemingway Measure of Adolescent Connectedness. Available online: http://adolescentconnectedness.com/survey.php (accessed on 12 May 2021).

29. Benner, A.D.; Mistry, R.S. Child Development During the COVID-19 Pandemic Through a Life-Course Theory Lens. Child Dev. Perspect. 2020, 14, 236-243. [CrossRef]

30. Viner, R.M.; Ross, D.; Hardy, R.; Kuh, D.; Power, C.; Johnson, A.; Wellings, K.; McCambridge, J.; Cole, T.J.; Kelly, Y.; et al. Life Course Epidemiology: Recognising the Importance of Adolescence. J. Epidemiol. Community Health 2015, 69, 719-720. [CrossRef] [PubMed]

31. Adodol, S.O.; Gbore, L.O. Prediction of Attitudes and Interest of Science Students of Different Ability on Their Academic Performance in Basic Science. Int. J. Psychol. Couns. 2012, 4, 68-72. [CrossRef]

32. Bakar, K.A.; Tarmizi, R.A.; Mahyuddin, R.; Elias, H.; Luan, W.S.; Ayub, A.F.M. Relationships Between University Students' Achievement Motivation, Attitude and Academic Performance in Malaysia. Procedia Soc. Behav. Sci. 2010, 2, 4906-4910. [CrossRef]

33. Sarwar, M.; Bashir, M.; Alam, M. Study Attitude and Academic Achievement at Secondary Level in Pakistan. J. Coll. Teach. Learn. 2010, 7. [CrossRef]

34. Guay, F.; Ratelle, C.F.; Roy, A.; Litalien, D. Academic Self-Concept, Autonomous Academic Motivation, and Academic Achievement: Mediating and Additive Effects. Learn. Individ. Differ. 2010, 20, 644-653. [CrossRef]

35. Zimmerman, B.J.; Bandura, A.; Martinez-Pons, M. Self-Motivation for Academic Attainment: The Role of Self-Efficacy Beliefs and Personal Goal Setting. Am. Educ. Res. J. 1992, 29, 663-676. [CrossRef] 
36. Hartnett, M. Relationships Between Online Motivation, Participation and Achievement: More Complex Than You Might Think. J. Open Flex. Distance Learn. 2012, 16, 28-41.

37. Khesht-Masjedi, M.F.; Shokrgozar, S.; Abdollahi, E.; Habibi, B.; Asghari, T.; Ofoghi, R.S.; Pazhooman, S. The Relationship Between Gender, Age, Anxiety, Depression, and Academic Achievement Among Teenagers. J. Fam. Med. Prim. Care 2019, 8, 799-804. [CrossRef]

38. Shankar, N.L.; Park, C.L. Effects of Stress on Students' Physical and Mental Health and Academic Success. Int. J. Educ. Psychol. 2016, 4, 5-9. [CrossRef]

39. Farooq, M.S.; Chaudhry, A.H.; Shafiq, M.; Berhanu, G. Factors Affecting Students' Quality of Academic Performance: A Case of Secondary School Level. J. Qual. Technol. Manag. 2011, 7, 1-14.

40. Wentzel, K.R.; Wigfield, A. Academic and Social Motivational Influences on Students' Academic Performance. Educ. Psychol. Rev. 1998, 10, 155-175. [CrossRef]

41. Masten, A.; Best, K.; Garmezy, N. Resilience and Development: Contributions from the Study of Children Who Overcome Adversity. Dev. Psychopathol. 1990, 2, 425-444. [CrossRef]

42. Gallardo, L.O.; Barrasa, A.; Guevara-Viejo, F. Positive Peer Relationships and Academic Achievement Across Early and Midadolescence. Soc. Behav. Pers. 2016, 44, 1637-1648. [CrossRef] 